ON

\section{CEREBRAL AND SPINAL PARALYSIS.}

\author{
By MIAPSHALL HALL, M.D., F.R.S.
}

WHEVEVR I have repeated my experiments on the condition of the irritability of the muscular fibre in paralytic limbs, on a considerable number of patients, $I$ have mets with exceptional cases. This fact $I$ have recorded on several occasions.

I noticed this event again particularly on my last trials at the St. Narylebone Infirmary in 1854. I called Dr. Reynolds' attention to the fact, and begged him to investigate the subject, and I think the profession greatly indebted to him for the deeplyinteresting results communicated in THE LANCET of the 8th instant.

I think all who have experimented on this subject, have agreed in one conclusion : the irritability is diminished in spinal paralysis, or that paralysis which, from whatever cause, (such is my definition of the term, ) excludes the influence of the spinal marrow.

It is in regard to cerebral paralysis that the difference of opinion has existed. I, with the exceptional cases to which I have alluded, and which I myself discovered, have found the irritability in this case augmented, comparatively, at least, with that of the other limb, if not positively; I believe the latter, though not in the degree in which it is diminished in the other form of puralysis.

The interesting question is - What is the explanation of the exceptional fact? For Le Gallois has a beautifnl paragraph-

"However opposed results may appear, we must remember, that of two facts, both well-established, one can never exclude the other, and that the apparent contradiction depends on some intermediate element which has escaped us."*

What is the "intermediate element" in regard to the question before us, in regard to which there is, as in all such cases, if the inquiry be pursued, a discovery to be made?

I believe I have made that discovery.

It consists in the fact that all cases of hemiplegia are not cases of cerebral paralysis.

These are not convertible terms. The very title, therefore of Dr. Reynolds' admirable paper is objectionable. Cerebral paralysis is one thing; hemiplegia, two or more!

For example: In a severe case of hemiplegia we meet with two series of phenomena. The first consists in paralysis of volition in the arm and leg of the side opposite to that of the lesion; this is cerebral paralysis. But there is a second. There are frequently stertor and dysphagia; these are symptoms of spinal paralysis. Further, the arm and leg themselves are sometimes so affected by spinal lesion, or by spinal shock, as to be at once affected by cerebral and by spinal paralysis. In such cases the phenomena of reflex action, and not the phenomena of $r \in f l e x$ action only, but the irritability must needs be impaired, according to the law which I have discovered.

This state of things becomes chronic. These severe and chronic cases, amongst the poor, are consigned to the workhouse. It is in the workhouse, therefore, that we meet with these exceptional cases chiefly.

In my first experiments my patients were chiefly private patients, and I particularly selected cases of distinct, but not too severe character - of moderate, but not too long durationof decided, but not absolute loss of voluntary power, and I only met with one exception to the law of augmented irritability in cerebral paralysis.

In my subsequent experiments, I made no selection of cases, and there were then several exceptional cases.

In my last experiments already alluded to, made in the institution in which Dr. Reynolds made his, again I met with several exceptional cases, although the number of my experiments was small, the fact which I mentioned to Dr. Reynolds, with the request which I have already noticed.

As to this idea of exception, although we use the term, I need scarcely observe that it is utterly erroneous. There can be no exception to a physiological law. An exception is an error-an ignorance.

Thus there can be no exception to the laws-1. That in pure cerebral paralysis there is augmented irritability; 2 . That in spinal paralysis there is diminution of this irritability.

Bat when we speak of hemiplegia, we use a term which does not always signify the same thing; which, in fact, sometimes signifies cerebral, and sometimes spincl paralysis, and the phenomena are in accordance with the things, not with the word.

The first error committed in this investigation, consisted in

* Sur le Principe de la Vie, Ed. 1812, p. xi. the wrong choice of an instrument. It was one of too great violence. The power and not the irritability of the muscles was tested.

The second error consists in the wrong choice of terms and of cases. Hemiplegia is sometimes purely cerebral paralysis; sometimes combined cerebral and spinal-a fact, in some degree new, resulting, as usual, from a new course of inquiry.

Cleared from all sources of ambiguity in the mode of experiment and in the use of terms, I repeat that my two laws in regard to the condition of the irritability of the muscular fibre in paralytic limbs remain-

1. In pure cerebral paralysis - that in which the influence of the cerebrum alone is removed--there is augmented irritability.

2. In spinal paralysis-that in which the influence of the spinal marrow is also removed-there is, and in a far greater degree, diminished irritability.

As corollaries from these facts become laws, I may repeat that the difference in the irritability of the muscles of the healthy and paralysed limbs in cerebral paralysis is the difference between muscles moved by volition, and muscles unexcited; whilst the difference in the irritability of muscles of healthy limbs and limbs affected by spinal paralysis, is the $a b$ sence or presence of the very source of this irritability, and of the other physiological conditions of these muscles. The difference in the degree of augmentation in the first case, and of the diminution in the second, is, therefore, perfectly intelligible to all.

To these statements may still be added the conclusion, that, duly employed, the galvanic current becomes a diagnostic-and it has often been a corrector of the previous diagnosis-between cerebral and pinal paralygis.

It is trying to think that after such distinct annunciations of the truth, we shall next read of paralysis - the cause of which is seated in the cerebrum, or in the spinal marrow, respectively, as synonymous with cerebral and with spinal paralysis. Whereas a disease seated in the cerebrum may extend its infuence to the spinal marrow, and produce spinal paralysis; and a disease not seated in the spinal marrow at all, but in the course of a spinal nerve, may, and does also, produce spinal paralysis, whilst a disease seated in the spinal marrow may produce cerebral paralysis.

We must accurately define, and stedfastly retain, our terms. For the present I will merely resume the cases thus:

In Cerebral Paralysis the affection is so limited as to exclude the influence of the cerebrum and cerebellum.

Hemiplegia, even of cerebral origin, if the disease be not limited, either in structure or influence, to the cerebrum and cerebellum, is not cerebral paralysis ; it is, pro tanto, spinal paralysis ; there are, at the least, two cases of this kind.

The pressure or other injury in regard to the medulla oblongata, denoted at first by stertor or dysphagia, may so continue as to induce and leave a form of spinal paralysis as these subside; the limb may be rigid (spasmo-paralysis) and deformed.

The shock inflicted on the spinal centre may be such as never to be recovered from; the limb is then flaccid.

The simplest case of cerebral paralysis is that arising from dirision of the spinal marrow ; all the limbs situated below this division are affected with cerebral paralysin.

Spinal Paralysis arises from any lesion, seated in any locality which excludes the influence of the spinal marrow. It may therefore be seated--primarily or secondarily in any part of the spinal marrow, whether 1 , within the cranium; or 2 , within the spinal canal; or 3 , in any part of the spinal nerves.

Recently, M. Duchenne has assumed that there are two kinds of general paralysis: one, in which the intellectual faculties are impaired; the other, in which there is no danger for those faculties; and that galvanism, as I have stated in regard to cerebral and spinal paralysis, affords a means of diagnosis. I suppose that as in the former the paralysis is cerebral, so in the latter it is spinal. M. Duchenne seems to have come round to my opinions, the difference now being, after all, as to whether the irritability in cerebral paralysis is persistent only or positively augmented, a question which the trials of Dr. Reynolds would seem to set at rest, at least in regard to a certain number of cases. M. Duchenne concludes-at a discussion at the Société de Médecine in Paris-by stating, "mon opinion sur ce sujet différe peu, on le voit, de celle du physiologiste Anglais."

There is a mode of investigation which I much wish to suggest. Disease is generally complicated. Experiment may be simple. I would propose to institute cerebral and spinal paralysis, pure and simple, on the dog, and then to experiment with the simplest form of galvanic influence at leisure. 
The first part of the experiment, as of most other physiological experiments, may be performed under the anæsthetic influence of chloroform. This last suggestion I make in the cause at ence of our own science and of humanity.

I propose shortly to add to these observations some remarks on some other forms of paralysis.

Cambridge-terrace, Hyde-park.

\section{a}

OF THE PRACTICE OF

\section{MEDICINE AND SURGERY IN THE}

\section{HOSPITALS OF LONDON.}

Nulla est alia pro certo noscendi via, nisi quam plurimas et morborum et dissectionum histurias, tam aliorum proprias, collectas habere et inter se comparare.-Morgigrr. De Sed. et Caus. MLorb. lib. 14. Procemium.

\section{QUARTERLY SUMMARY \\ OF}

\section{PRINCIPAL OPERATIONS AND CASES IN THE HOSPITALS}

DURING JULY, AUGUST, AND SEPTEMBER.

\section{CUTANEOUS DISEASES, SPECIFIC SORES, \&C.}

1. The case of "keloid" noticed by us before, (THE LANCet, vol. i. 1855, p. 239,) has again been under treatment in Guy's Hospital, and appears, at present, to be very considerably benefited by the liquor potasse and other alterative remedies ordered by Dr. Addison.

2. In a second case of this very obstinate malady, that of a girl, aged fifteen, Mr. Hilton removed some of the tuberous growths with apparently good results.

3. A case of eczema, sent by some inadvertence to the syphilitic ward of St. Bartholomew's Hospital, gave rise to some interesting clinical remarks by Mr. Paget on the 22nd of August, and was then placed under treatment by cod-liver oil applied externally with the very best effect. Mr. Paget seemed to think that secondary syphilis avoids the vesicular forms of syphilitic eruptions. Why it should be so, does not so plainly appear. Eczema, as a general rule, he finds to yield to the exhibition of cod-liver oil steadily followed out.

4. A case of obstinate tertiary syphilitic sore has been under Mr. Erichsen's care in University College Hospital some time. The man has been taking hot decoction of sarsaparilla, as directed by Mr. Langston Parker in the treatment of this affection, and has thus been constantly preserved in a state of perspiration. We were not very much struck with the signs, if any, of improvement; indeed, if there be any virtue in sarsaparilla, it was not shown here.

5. A case of very painful interest was received into the Middlesex Hospital early in August, - well-marked glanders, contracted by a poor woman from her husband's horses, one of which, it seems, had been for some time ill of this horrible disease. Mr. Wormald tells us he has known the affection, in its early stage, or in the form of what are called "farcy buds," situated along the glands of the arm or other parts, to be readily cured by iodide of potassium. The chief chance of remedying the disease is attacking it early with the iodide.

6, 7. Mr. Wormald, at St. Bartholomew's Hospital, is a great adrocate for mercury, carefully given, in all forms of syphilis. Even tertiary and secondary syphilis, which he take to be partly due to the neglect of the specific, he has found in innumerable cases to yield at once to diet, and properlyregulated doses of mercury. The external inunction of mercury, and the internal use of mercury, according to Mr. Wormald, are two entirely different things, and sores which will yield to one method will often remain stationary, if not retrograde, under the other. Two cases, out of several now in St. Bartholomew's, in Mr. Lawrence's ward, seem to corroborate these views. Mr. Wormald, from thirty years' experience in the above hospital, has come to the conclusion, that the internal use of calomel, or of large doses of mercury in primary syphilis, in secondary sores, and, above all, in phagedænic sores, so dis turbs the chylopoietic functions of the stomach and duodenum as to defeat its own purpose, while the external inunction of mercury, or fumigations, or grain-doses of blue pill, as ordered by Mr. Abernethy, whose practice, he thinks, has never been improved, will, in ninety-nine cases out of one hundred, be followed by cure. Iodide of potassium and sarsaparilla seem to exert a temporary effect on syphilitic eruptions; but Mr. Wormald believes these eruptions only come ont again and again till the specific poison of the disease be removed by mercury. Some most striking cases have been related to us as occurring to Mr. Wormald, where, in obstinate secondary symptoms, the result of the poison of mercury and syphilis, all difficulty vanished on getting the system under a mild mercurial course by external inunction; the over-dosing system, or "throwing in the mercury," on the other hand, so deranges the stomach and digestion, while it at the same time, so to speak, poisons all parts of the system but that where the syphilitic poison is at work-namely, in the lymphatics about the groin, that mercury too often does more harm than good, preventing the reparative process in phagedænic and other sores.

\section{LITHOTOMY.}

Six operations of this kind out of about twelve we have seen deserve notice.

1,2. Two cases of lithotomy were performed in August, in which the practical value of the scoop as an essential part of the armamenta chirurgica of this operation was very well shown; one a case of lithotomy by Mr. Fergusson, in which at first great difficulty existed in de tecting the calculss on some days, but on other days it was quite perceptible to the sound. Mr. Fergusson, we observed at the operation, at one single incision and without removing the knife, cut down and got into the groove of the staff, and on into the neck of the bladder, but no stone, in the ordinary acceptation of the term, was to be felt, nor did Mir. Fergusson use the forceps, but passed his finger round carefully, when a little wart-like excrescence, like the tip of a little finger with its nail, was per. ceptible behind the prostate. The remaining part of the stone, the size of a nutmeg, being firmly buried in a cyst in the bladder. Mr. Fergusson does not approve of cutting such cysts, but by gradually insinuating the small scoop round and beneath the calculus, he finds it easy to manipulate so as effectually to remove the calculus, which he succeeded in doing in the present case quite satisfactorily.

The second was a case in which Mr. Cock operated at Guy's, admirably adapted for " Allarton's operation," as observed at the time, where also some difficulty was experienced in finding the stone one day while there was no difficulty on other days; the stone, though very hard, was not larger than a split pea, and would have escaped the grasp of the forceps, but was readily caught up, as if by a spoon, in the small-sized scoop.

3. In a third case, Mr. Cock also removed another stone. On cutting into the parts, the stone felt almost like a broken walnut shell impacted across the neck of the bladder, and not so easily removed by the forceps as the fingers.

4. H. R_, a boy, aged nine years, was also admitted into Guy's in August, and operated on by Mr. Hilton. This case did very well, though at first there was very severe hæmor rhage. The stone was unusually large. Mr. Hilton employed a means of arresting the hæmorrhage, which has now been some time in use at Guy's and found to be very effectual. We shall give the best idea of it perhaps by saying, it may be extemporised by any surgeon from an ordinary enema pipe, and a very small bladder (the old fistula armata), by tying the bladder two-thirds of the way up the pipe. The latter is then carefully inserted into the wound of the prostate, allowing the urine to flow away through it; the cul de sac of loosish membrane, also, as pushed along the wound, is then either dilated with air, thus acting on the principle of some pessaries, and pressing on the bleeding vessels, or, what is better, the cul do sac is filled with pounded ice and iced water, which seldom fail to check the hæmorrhage.

5. G. H-, a man in a fair state of health was operated on also by Mr. Hilton, about the same time. Not for lithotomy, in the ordinary acceptation of the term, as now inseparately associated with Cheselden's operation, but for stone impacted in the urethra and of some nine months' growth. Mr. Hilton made a clean vertical incision in the middle line of the perinæum, when two stones, the size of small nuts or almonds, were extracted; one had been quite bevelled off or indented to fit 